\title{
Further experience of Corynebacterium parvum in malignant pleural effusion
}

\author{
DT MCLEOD, PMA CALVERLEY, JW MILLAR, NW HORNE \\ From the Chest Unit, City Hospital, Edinburgh, and Poole General Hospital, Poole, Dorset
}

ABSTRACT The outcome of drug induced pleurodesis has been evaluated in a non-randomised retrospective study of 67 patients with recurrent malignant pleural effusions treated during 1976-83. Fourteen died within 30 days of treatment. Of the remaining 53 patients, 26 studied during 1976-80 were treated with intrapleural mustine hydrochloride, while 27 studied during 1978-83 were treated with intrapleural Corynebacterium parvum. There was no significant difference between the groups in age, sex, or tumour type, most tumours being secondary to bronchial neoplasms. Corynebacterium parvum successfully prevented reaccumulation of the effusion in $24(92 \%)$ patients, while mustine was effective in only $17(65 \%)(\mathrm{p}<0.05)$. Data on survival were obtained on 47 cases where a single agent was used to induce pleurodesis. In 25 patients treated with $C$ parvum the mean survival was 251 (range 31-1143) days, compared with 119 (range 31-380) days for the 22 patients in whom mustine was used. Survival of the $C$ parvum group was significantly greater $(\mathrm{p}<0.01)$. The difference was principally due to the greater number of long term survivors in the $C$ parvum group, nine of this group living for more than 180 days (mean 574, range 180-1143 days) compared with only four such survivors in the mustine group (mean 263, range 193-380 days). This study confirms our initial impression that $C$ parvum is highly effective in controlling recurrent malignant pleural effusions. The finding of unexpected long term survivors with $C$ parvum treatment suggests that this treatment may have an additional effect on the progression of disease, a finding that merits further investigation.

Pleural effusion is a common complication of advanced cancer ${ }^{1}$; it is often symptomatic and carries a poor prognosis. ${ }^{2}$ Pleural aspiration is normally undertaken to relieve symptoms and this is often followed by the instillation of an agent to promote pleurodesis and prevent reaccumulation. Several different methods and agents ${ }^{3-7}$ have been advocated. In 1980 we reported a randomised study of intrapleural Corynebacterium parvum compared with the previous standard treatment of intrapleural mustine hydrochloride in patients with recurrent malignant pleural effusions presenting to a respiratory unit. ${ }^{8}$ As $C$ parvum was effective and relatively free from side effects we now routinely use this agent in such patients. It became apparent that some patients had an unexpectedly long survival after $C$ parvum treatment. We have therefore reviewed our

Address for reprint requests: Dr DT McLeod, North Tees General Hospital, Hardwick, Stockton on Tees, Cleveland.

Accepted 11 February 1985 recent experience with $C$ parvum in malignant pleural effusion and compared the survival of these patients with that of similar patients treated with mustine.

\section{Methods}

A retrospective analysis was made of two groups of patients with recurrent pleural effusion associated with proved malignant disease and treated with either mustine hydrochloride or Corynebacterium parvum. From 1976 to $197820 \mathrm{mg}$ intrapleural mustine hydrochloride was routinely used. In 1978 a randomised study comparing $20 \mathrm{mg}$ mustine hydrochloride with $7 \mathrm{mg}$ intrapleural Corynebacterium parvum showed the latter to be more effective with relatively fewer side effects. During this study period (1978-80) if one agent failed the other was tried. Thereafter $C$ parvum replaced mustine as our primary pleurodesing agent. Before 1980 we used formalin fixed $C$ parvum but since then we have used a heat killed, freeze dried preparation. This 
change reflected an alteration in manufacturing policy.

Pleural biopsy and cytological examination of pleural fluid were performed in every case. Those patients in whom no malignant cells were seen underwent bronchoscopy in an attempt to establish a tissue diagnosis.

All patients required at least two previous aspirations because of rapid fluid accumulation, and all had dyspnoea, cough, or local pain due to the effusion. A standard procedure was adopted throughout. After aspiration to dryness through a wide bore thoracocentesis needle the pleurodesing agent was instilled and the patient tilted on the bed in several directions, each position being held for 15 minutes to ensure widespread distribution over the lung surface. Intercostal drainage was not used before or after instillation. Symptoms of local pain, fever, nausea, and vomiting were documented for 48 hours after each instillation and fluid reaccumulation was assessed with regular chest radiographs. A further dose of pleural adhesing agent was given if a repeat aspiration proved necessary for the relief of symptoms. The procedure was considered completely successful if only one treatment was necessary; if a second aspiration was required treatment was deemed a partial success. More than two aspirations constituted a treatment failure. Patients surviving for less than 30 days after instillation of the pleural adhesing agent were not included in the analysis in either series as it was felt that treatment was unlikely to have influenced their survival, and that the survival time was too short for adequate assessment of successful pleurodesis. Patients who failed with one agent and were subsequently treated with the other were not included in the analysis of survival.
The effectiveness of each agent in producing pleurodesis was compared using the $\chi^{2}$ test with Yates's correction. The Wilcoxon rank sum test was used to compare survival of the different treatment groups in this series and also the survival of those patients previously reported. ${ }^{8}$

\section{Results}

From 1976 to 198367 patients (including 20 who participated in the randomised trial ${ }^{8}$ ) were treated, 34 with $C$ parvum and 33 with mustine. Seven patients from each treatment group died within 30 days of treatment. Of the remaining patients, 27 (15 male and 12 female; mean age 69, range 34-90 years) were treated with $C$ parvum and 26 patients ( 16 male and 10 female; mean age 70 , range 49-82) received mustine hydrochloride.

The two treatment groups were similar as regards age, sex, and range of cell type (table), although in six patients receiving mustine the effusion was diagnosed as malignant on the basis of endoscopic appearances and clinical course rather than cytological examination. The size of the effusion, aspiration volume, and interaspiration intervals was similar in the two study groups. In the $C$ parvum group $70 \%$ had primary pulmonary tumours, compared with $65 \%$ in the mustine group, the remainder comprising metastatic deposits from renal, bladder, ovarian, stomach, colon, and breast carcinoma. $C$ parvum produced 23 complete successes, one partial success, and two failures. In one patient a collapsed lung resulted from total bronchial occlusion with tumour. The overall success rate with $C$ parvum was thus $92 \%$. In the 26 patients treated with mustine, there were 13 complete successes, four partial successes,

Tumour cell types in all patients surviving more than 30 days (column $\dot{A}$ ) and in those surviving more than 180 days after treatment with Corynebacterium parvum or mustine

\begin{tabular}{|c|c|c|c|c|}
\hline & \multicolumn{4}{|c|}{ No of patients } \\
\hline & \multicolumn{2}{|c|}{ C parvum } & \multicolumn{2}{|c|}{ Mustine } \\
\hline & $A$ & $B$ & $\boldsymbol{A}$ & $B$ \\
\hline \multicolumn{5}{|l|}{ Primary pulmonary tumour } \\
\hline Squamous & 9 & 2 & 2 & \\
\hline Large cell & 2 & 1 & 1 & \\
\hline Adenocarcinoma & 3 & 2 & 4 & 1 \\
\hline Small cell & 4 & & 3 & \\
\hline Mesothelioma & 1 & 1 & 1 & 1 \\
\hline Unclassified malignant cell type & 4 & 1 & $10^{*}$ & 1 \\
\hline \multicolumn{5}{|l|}{ Adenocarcinoma metastases } \\
\hline Breast & 1 & & 0 & \\
\hline Colon & 0 & & 1 & \\
\hline Stomach & 0 & & 1 & 1 \\
\hline Ovary & $2 \dagger$ & 2 & 1 & \\
\hline Renal & 1 & & 1 & \\
\hline Bladder & 0 & & 1 & \\
\hline
\end{tabular}

* Six of these patients had tumours at bronchoscopy.

tOne patient is still living (after 3.5 years). 
and nine failures. With an overall success rate of $65 \%$ mustine was significantly less successful than $C$ parvum $(\mathrm{p}<0.05)$.

Success with either sclerosing treatment was not obviously related to tumour cell type. All patients treated with mustine were nauseated and most vomited, in addition to experiencing local chest pain. Intrapleural $C$ parvum gave rise to fever $\left(38^{\circ} \mathrm{C}\right)$, which undulated for two to three days, in seven (32\%) patients. A similar number experienced chest pain, which was readily controlled with simple analgesics and did not last for more than 24 hours. Nausea was experienced by only a few and no patients vomited.

The mean survival in the 25 patients treated solely with $C$ parvum was 251 (median 120) days compared with 119 (median 120) days in the 22 patients treated with mustine alone. This difference was largely due to the greater number of long term survivors in the $C$ parvum group, nine patients living for more than 180 days (mean survival 574 , median 448 , range $180-1143$ days) compared with only four mustine treated patients (mean survival 263, median 240, range 193-380 days). Overall survival was significantly longer in the $C$ parvum group ( $\mathrm{p}<$ 0.01 ). In contrast, in patients living for less than 180 days, there was little difference in survival between the two groups (fig). Among patients included in the original randomised study comparing $C$ parvum with mustine treatment, ${ }^{8}$ survival was again significantly prolonged $(p<0.01)$ in those treated with $C$ parvum. The mean survival with $C$ parvum was 246 days (median 147, range 64-1143 days) and three patients survived longer than 180 days. With mustine the mean survival was 97 days, (median 120, range $31-150$ days).

The two groups were comparable in respect of treatment offered in addition to pleurodesis; five

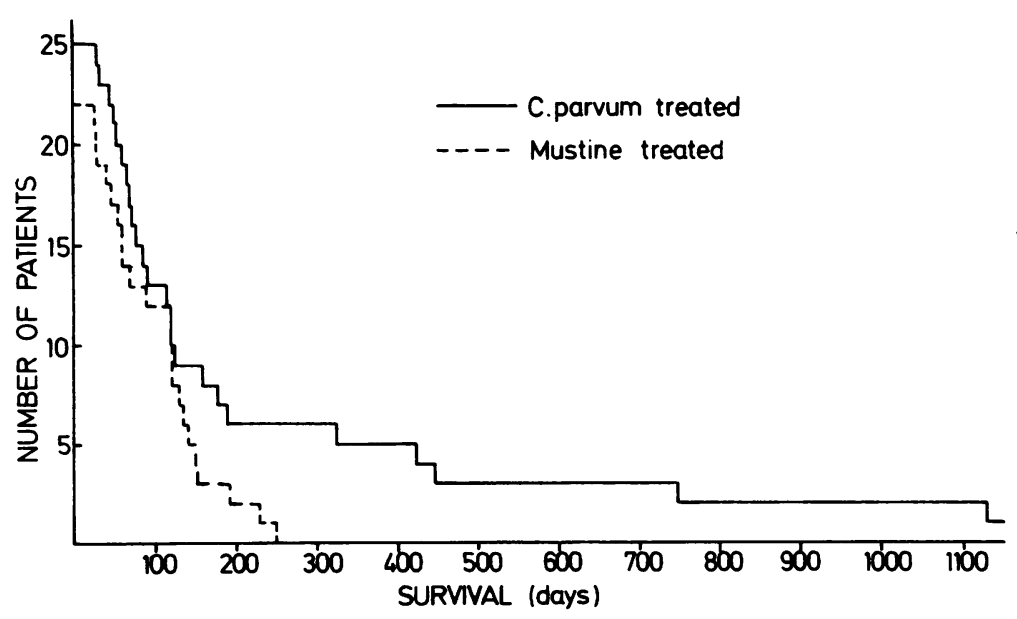

patients in the $C$ parvum group and four in the mustine group received radiotherapy and two in each group received supplementary cyclophosphamide. Of the nine patients surviving more than 180 days who were treated with $C$ parvum, three received radiotherapy but in only one case might this have prolonged survival. This patient had squamous cell carcinoma while the other two were probably unaffected, their tumours being adenocarcinomas of the bronchus. The remaining six patients received no additional treatment.

\section{Discussion}

This study of a larger number of patients confirms our initial findings $\mathrm{s}^{8}$ that $C$ parvum is a significantly more effective pleurodesing agent than mustine hydrochloride and is better tolerated. In this retrospective analysis the two agents were in the main administered at different times, most patients treated before 1980 receiving 20 mg mustine while after 1980 most received $C$ parvum $7 \mathrm{mg}$. Other aspects which might have affected the results were, however, unaltered; there was a standard technique for instillation of the agents and standard care and supervision of patients. Furthermore, we could find no evidence of any change in referral pattern of patients with pleural effusion in this period; this is supported by the similarity in age distribution and pathological type in the two studies, the improvement in histopathological diagnosis in the latter group reflecting a general improvement in diagnostic techniques over this period. The mustine treated group contained more patients without definite pleural lesions (6/33) and some of these might have lacked true pleural invasion by tumour. Such patients have, however, a poor prognosis and at thoracotomy would be expected to have evidence of 
pleural or mediastinal tumour. ${ }^{9}$ So far as we could tell there was no difference between the groups in the extent of intrapulmonary tumour or extrapulmonary metastases.

The high rate of pleurodesis successful usually at the first attempt in patients treated with $C$ parvum was achieved without the need for a pleural drain, with its attendant pain and morbidity; the outcome is similar to the best results reported in comparable patients treated with drains and other agents. ${ }^{3-7}$ Two other series have achieved similar good results with $C$ parvum, with successful pleurodesis in $79 \%$ and $90 \%$ of patients. ${ }^{1011}$ The results of mustine instillation were also similar to those in previous reports, showing, by contrast, about $60 \%$ efficacy $^{12}$ and a relatively high morbidity rate.

$C$ parvum excites such a vigorous inflammatory reaction in the pleural space that bizarre chest radiographic appearances may devlop over a period of months and be mistaken for tumour extension or fluid reaccumulation. At necropsy an uneven, grossly thickened cortex of fibrous tissue is seen over the lung surface. No symptoms occurred despite these appearances.

Although detailed information about survival in malignant pleural effusions is available, it is difficult to compare groups where there are large differences in tumour types and the numbers studied are small. Most series agree that survival is short, mean survival being 3.1 (SD 0.5) months in one large series. ${ }^{2}$ This is similar to that seen in our mustine treated patients, whose mean survival was 119 (median 120 , range 31-380) days. In contrast, patients treated with $C$ parvum lived for a mean of 251 (median 120 , range 31-1143) days. Survival in this group was significantly greater at the $1 \%$ level. These figures, however, disguise the true pattern of attrition seen in the figure. Over the first six months after $C$ parvum treatment there was no significant difference in survival, but subsequently $C$ parvum treated patients survived for much longer periods. The differences in the cell types of our study groups, with a preponderance of squamous carcinoma in the $C$ parvum group, may be more apparent than real. Ten of the mustine treated patients were reported as having " unclassified malignant cells," reflecting the tendency in the mid 1970s to report cytological findings without further subclassification. Given the usual distribution of cell types among these "unclassified" patients, at least five would be expected to be squamous carcinoma and our groups would be more comparable. A similar uncertainty surrounds the one "unclassified" long term survivor. Certainly prolonged survival after $C$ parvum was not confined to the patients with squamous cell carcinoma; if anything it was proportionately less frequent. Although there is a large intersubject variation in response to tumour, which itself varies with cell type, we believe that the more prolongd survival of patients in the $C \bar{C}$ parvum group, not confined to any age group or histological type, raises the possibility that $C$ parvum may be acting as more than simply a sclerosant.

In summary, we have found $C$ parvum to be a highly effective and safe method of controlling malignant pleural effusions. In addition, some $\odot$ patients treated with $C$ parvum had an unexpectedly long survival after diagnosis, which may be due to a direct effect on tumour growth. This possibility $\vec{x}$ should be explored by further prospective studies.

We are grateful to Mrs Sheila Black for her invalu- $\mathcal{O}$ able help in tracing hospital records and to Miss $\vec{G}$ Joyce Holywell for typing the manuscript.

\section{References}

1 Dhillon DP, Spiro SG. Malignant pleural effusions. $\mathrm{Br}$ J Hosp Med 1983;29:506-11.

2 Chernow B, Sahn SA. Carcinomatous involvement of the pleura. Am J Med 1977;63:695-702.

3 Lambert CJ, Shah HH, Urschel HC, et al. The treatment of malignant pleural effusion by closed trocar tube drainage. Ann Thorac Surg 1967;3:1-5.

4 Jones GR. Treatment of recurrent malignant pleural effusion by iodised talc pleurodesis. Thorax 1969;24:69-73.

5 Rubinson RM, Bolooki H. Intrapleural tetracycline for control of malignant pleural effusion. South Med J 1972;65:847-9.

6 Paladine W, Cunningham TJ, Sponzo R, Donovan M, Olson $\mathrm{K}$, Horton $\mathrm{J}$. Intracavitary bleomycin in the management of malignant effusions. Cancer 1976;38: 1903-8.

7 Stiksa G, Korsgaard R, Simonsson BG. Treatment of 9 recurrent pleural effusions by pleurodesis with quinacrine. Scand J Respir Dis 1979;60:197-205.

8 Millar JW, Hunter AM, Horne NW. Intrapleural immunotherapy with Corynebacterium parvum in o recurrent malignant pleural effusions. Thorax 1980;35:856-8.

9 Decker DA, Dines DE, Payne WS, Barnatz PE, N Pairolero PC. The significance of a cytologically negative pleural effusion in bronchogenic carcinoma. Chest 1978;74:640-2.

10 Honeybourne D, Leahy BC, Brear SG, Carrol KB, Stretton TB, Thatcher N. Randomised study of intra- : pleural Corynebacterium parvum versus tetracycline $T$ for malignant pleural effusions. Thorax 1983;38:228.

11 Felletti R, Ravazzoni C. Intrapleural Corynebacterium parvum for malignant pleural effusions. Thorax 1983;38:22-4.

12 Levison VB. Nitrogen mustard in the palliation of malignant effusions. Br Med J 1961;i:1143-5. 